\title{
Computer Simulation of Biodiesel Production By Hydro-esterification
}

\author{
G. D. MACHADO ${ }^{1}$, F. L. P. PESSOA ${ }^{1}$, M. CASTIER ${ }^{2}$, D. A. G. ARANDA ${ }^{1}$, L. FERREIRA- \\ PINTO $^{3}$, W. M. GIUFRIDA ${ }^{3}$, V. F. CABRAL ${ }^{3}$ e L. CARDOZO-FILHO ${ }^{3}$. \\ ${ }^{1}$ Universidade Federal do Rio de Janeiro, Departamento de Engenharia Química \\ ${ }^{2}$ Chemical Engineering Program, Texas A\&M University at Qatar \\ ${ }^{3}$ Universidade Estadual de Maringá, Departamento de Engenharia Química \\ E-mail para contato: guilherme.duenhas@gmail.com
}

\begin{abstract}
The conventional production method of this biofuel, by transesterification in two stages, chemical reaction and product separation, has several disadvantages. Biodiesel production by hydro-esterification reaction from fatty matter with has attracted much attention because of its many advantages, but available technology still requires distinct steps for reaction and separation. This work presents computational simulations of a multi-step process of soybean oil biodiesel production by hydro-esterification. For the hydrolysis step, a packed bed reactor (PBR) was chosen. For the esterification step, a reactive distillation column (RDC) is used, with reaction and separation in the same piece of equipment. The simulation results show that the methodology used is consistent and sensitivity analyses suggest that conversions close to $99 \%$ are possible.
\end{abstract}

\section{INTRODUCTION}

The main route of commercial industrial production of biodiesel is based on the transesterification of refined oils by alkaline catalysts, such as sodium alkoxides and potassium, since the process is relatively simple to use and reaches conversion values above 95\% (Ma and Hanna, 1999). However, this route has problems, mainly in the purification step, that cause income losses and waste generation.

The use of heterogeneous catalysts can potentially reduce the cost of biodiesel production, making it competitive against fossil diesel. They facilitate the purification of monoesters, the reuse of the solid catalyst, minimize waste generation, decrease reaction time, yield higher conversions, and allow for the use of low quality raw materials, thereby reducing costs (Aranda et al., 2009).

Hydro-esterification consists of a step of vegetable oil hydrolysis, followed by subsequent esterification of fatty acids produced. Both steps can be accelerated by acid catalysts and become more attractive when coupled to the use of heterogeneous catalysts, eliminating soap formation, reducing the number of separation units, enabling catalyst reuse, and producing high purity, salf-free glycerin (Aranda et al., 2009). The great advantage of hydro-esterification compared to transesterification is that the free fatty acid is reactant in the same reaction, thus not being a limitation in terms of specification of raw material (Lotero et al., 2005; Di Serio et al., 2008). 


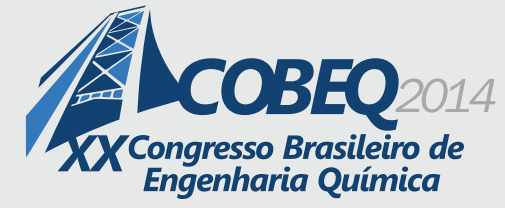

In this sense, hydrolysis processes are known and well established, with current operation on industrial scale. Moreover, the esterification step of fatty acids still has a number of technical challenges regarding the mode of operation (batch or continuous). Thus, it opens up opportunity to use reactive distillation column (RDC) technology to the esterification step. Reactive distillation is a hybrid operation that combines physical separation and chemical reaction in the same piece of equipment. Works as Kiss (2009) and Machado et al. (2013) show the use of this technology for the esterification of fatty acids to esters as biodiesel.

This work presents computer simulations of a continuous multi-stage process for the production of soybean oil biodiesel by hydro-esterification. The hydrolysis reaction is performed in a Packed Bed Reactor (PBR), while the esterification step is conducted in a Reactive Distillation Column (RDC). In both cases, sensitivity analyses of design parameters and operating conditions are performed in order to optimize the operation of each step.

\section{METHODOLOGY}

\subsection{Hydrolysis}

The choice of the tubular reactor for the hydrolysis step was based on the fact that this reaction is conducted at severe conditions (high pressure and temperature). A mass balance in the differential catalyst mass element $\mathrm{dW}$ for the component $\mathrm{A}$, involved in one single reaction over the total weight of catalyst W, the tubular reactor can be described as in Figure 1.

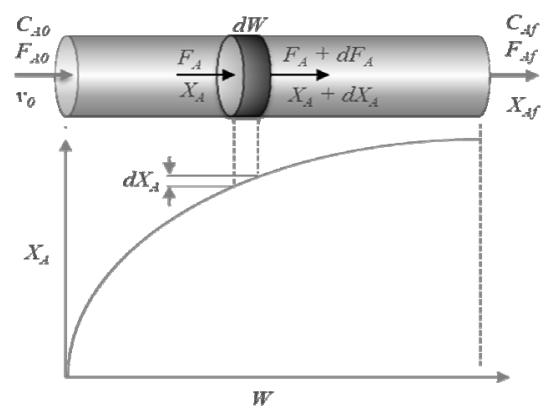

Figure 1: Schematic of a differential mass element dW in a PBR. (adapted from Fogler, 2002)

Based on Figure 1, a mass balance for component A can be performed by the following equation, where $\mathrm{F}_{\mathrm{A}}$ and $\mathrm{X}_{\mathrm{A}}$ are molar feed and conversion for component $\mathrm{A}$, respectively:

$$
F_{A}-\left(F_{A}+d F_{A}\right)=r_{A}{ }^{\prime} d W
$$

It can be rewritten in terms of the conversion of component $\mathrm{A}, \mathrm{X}_{\mathrm{A}}$, leading to: 


$$
F_{A}=F_{A 0}\left(1-X_{A}\right)
$$

Its integrated form is the project equation of a tubular reactor.

$$
\frac{W}{F_{A 0}}=\int_{0}^{X_{A}} \frac{d X_{A}}{r_{A}{ }^{\prime}}
$$

The solid mass must be used because the amount of catalyst is important for the reaction speed. Following the strategy of Fogler, (2002), the project equation reduces to a differential equation which relates the conversion of component $\mathrm{A}$ based on the mass $\mathrm{W}$ of the catalyst distributed along the tubular reactor.

$$
W=\frac{v_{0}^{2}}{F_{A 0}} \int_{o}^{X_{A}} \frac{d X_{A}}{k_{01} \exp \left(\frac{-E_{a I}}{R T}\right)\left(1-X_{A}\right)\left(\theta_{B}-\frac{b}{a} X_{A}\right)-k_{0-1} \exp \left(\frac{-E_{a-1}}{R T}\right)\left(\theta_{C}-\frac{c}{a} X_{A}\right)\left(\theta_{D}-\frac{d}{a} X_{A}\right)}
$$

Where $v_{0}$ is molar flow, $\mathrm{k}_{0}$ and $\mathrm{E}_{\mathrm{a}}$ are Arrheinus equation parameters. Equation 4 is numerically integrated along the catalyst mass of the tubular reactor, resulting in a composition of components throughout the equipment by specifying the mass of catalyst and reactor feed flow, for known kinetic constants in function of temperature.

\subsection{Esterification}

The modeling of the esterification step is based on considerations of Chen et al. (2000), Alfradique and Castier (2005) and Machado et al. (2013) for the simulation of reactive distillation columns. The scheme of the generic plate adopted in this work is shown in Figure 2:

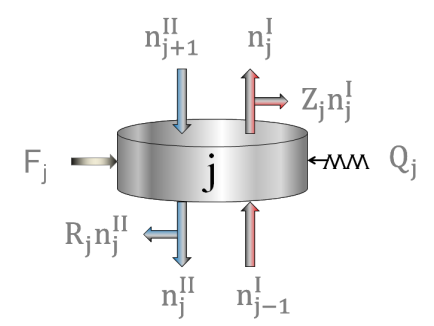

Figure 2: Configuration of stage $\mathrm{j}$ in reactive distillation column (Alfradique and Castier, 2005).

From Figure 2, residue equations of the mass balance, phase equilibrium, reaction rate, energy balance and vapor-liquid ratio can be established:

$$
\mathrm{f}_{\mathrm{i}, \mathrm{j}}^{\mathrm{m}}=\left(\mathrm{R}_{\mathrm{j}}+1\right) \mathrm{n}_{\mathrm{i}, \mathrm{j}}^{\mathrm{II}}+\left(\mathrm{Z}_{\mathrm{j}}+1\right) \mathrm{n}_{\mathrm{i}, \mathrm{j}}^{\mathrm{I}}-\left(\mathrm{n}_{\mathrm{i}, \mathrm{j}+1}^{\mathrm{II}}+\mathrm{n}_{\mathrm{i}, \mathrm{j}-1}^{\mathrm{I}}+\mathrm{F}_{\mathrm{i}, \mathrm{j}}+\sum_{\mathrm{k}=1}^{\mathrm{nr}} v_{\mathrm{i}, \mathrm{k}} \xi_{\mathrm{k}, \mathrm{j}}\right)=0
$$




$$
\begin{aligned}
& \mathrm{f}_{\mathrm{i}, \mathrm{j}}^{\mathrm{eq}}=\ln \left(\mathrm{x}_{\mathrm{i}, \mathrm{j}}^{\mathrm{I}} \mathrm{P}_{\mathrm{j}}\right)-\ln \left(\mathrm{x}_{\mathrm{i}, \mathrm{j}}^{\mathrm{II}} \gamma_{\mathrm{i}, \mathrm{j}}^{\mathrm{II}} \mathrm{P}_{\mathrm{i}, \mathrm{j}}^{\mathrm{sat}}\right)=0 \\
& \mathrm{f}_{\mathrm{k}, \mathrm{j}}^{\mathrm{r}}=\ln \mathrm{l}_{\mathrm{k}, \mathrm{j}}+\sum_{\mathrm{i}}^{\mathrm{nc}} \alpha_{\mathrm{i}, \mathrm{k}} \ln \left(\mathrm{x}_{\mathrm{i}, \mathrm{j}}^{\mathrm{II}} \gamma_{\mathrm{i}, \mathrm{j}}^{\mathrm{II}}\right)-\ln \xi_{\mathrm{k}, \mathrm{j}}=0 \\
& \mathrm{f}_{\mathrm{j}}^{\mathrm{h}}=\left(\mathrm{R}_{\mathrm{j}}+1\right) \mathrm{H}_{\mathrm{j}}^{\mathrm{II}}+\left(\mathrm{Z}_{\mathrm{j}}+1\right) \mathrm{H}_{\mathrm{j}}^{\mathrm{I}}-\left(\mathrm{H}_{\mathrm{j}+1}^{\mathrm{II}}+\mathrm{H}_{\mathrm{j}-1}^{\mathrm{I}}+\mathrm{H}_{\mathrm{F}_{\mathrm{j}}}+\mathrm{Q}_{\mathrm{j}}\right)=0 \\
& \mathrm{f}_{\mathrm{j}}^{\mathrm{vl}}=\left(\mathrm{Z}_{\mathrm{j}}+1\right) \sum_{\mathrm{i}=1}^{\mathrm{nc}} \mathrm{n}_{\mathrm{i}, \mathrm{j}}^{\mathrm{I}}-\mathrm{E}_{\mathrm{j}}\left(\mathrm{R}_{\mathrm{j}}+1\right) \sum_{\mathrm{i}=1}^{\mathrm{nc}} \mathrm{n}_{\mathrm{i}, \mathrm{j}}^{\mathrm{II}}=0
\end{aligned}
$$

These residue functions, the Jacobian matrix and the activity coefficient models were generated using the Thermath program (Castier, 1999). The UNIFAC Dortmund model (Gmehling et al., 1993) is used to describe the non-ideal liquid phase behavior. The mathematical formulation was implemented using the programming language FORTRAN 77. Additional details about the solution method are available in the work of Alfradique and Castier (2005).

\section{RESULTS}

\subsection{Hydrolysis}

The hydrolysis of soybean oil (1) with water, (2) producing hydrolyzate (3) and glycerol (4) takes place according to the following stoichiometry:

$$
\text { Soybean Oil (1) }+3 \cdot \mathrm{H}_{2} \mathrm{O}(2) \Leftrightarrow 3 \cdot \text { Hydrolyzate (3) }+\mathrm{C}_{3} \mathrm{H}_{8} \mathrm{O}_{3}(4)
$$

Soybean oil and Hydrolyzate properties took into account the composition of the main fatty acids constituent present in soybean oil. In kinetic terms, the hydrolysis reaction is considered reversible. The rate model used is the pseudo-homogeneous with dependence of the molar concentrations of the reactants. The subscripts are as seen in equation 11:

$$
r^{\prime}=k_{1} C_{1} C_{2}-k_{2} C_{3} C_{4}
$$

The kinetic data of the hydrolysis and esterification reactions were obtained by Rocha et al. (2010) who used niobium oxide as catalyst. The specifications of the reactor and the constants of the reaction rate equation for the catalyst are given in Table 1.

Figure 3 displays the liquid phase component mole fractions along the simulated PBR and Figure 4 shows the liquid phase molar composition surface of soybean oil as function of the feed flow (a) and feed molar ratio of water / soybean oil (b), respectively. 
Table 1 - Specification for PBR and hydrolysis reaction

\begin{tabular}{|c|c|c|}
\hline Variables & \multicolumn{2}{|c|}{ Specifications } \\
\hline Pressure & constant & $56 \mathrm{bar}$ \\
\hline Temperature & constant & $260^{\circ} \mathrm{C}$ \\
\hline \multirow{2}{*}{ Dimensions } & length & $139 \mathrm{~cm}$ \\
\cline { 2 - 3 } & diameter & $12 \mathrm{~cm}$ \\
\hline \multirow{2}{*}{ Feed } & $\mathrm{v}_{0}$ & $0.13 \mathrm{~m}^{3} / \mathrm{min}$ \\
\cline { 2 - 3 } & Molar ratio & 5.7 \\
\hline Ahrrenius & Pre-exponential fator & $156.90 / 2.42$ \\
\hline Parameters & Activation energy & $-40,421.9 \mathrm{~J} / \mathrm{mol}$ \\
\hline
\end{tabular}

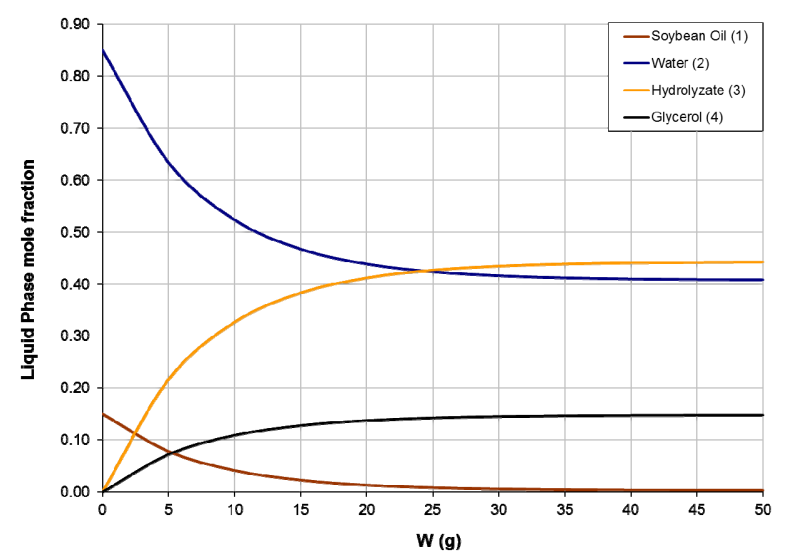

Figure 3 - Liquid phase mole fraction of components to hydrolysis reaction along PBR.
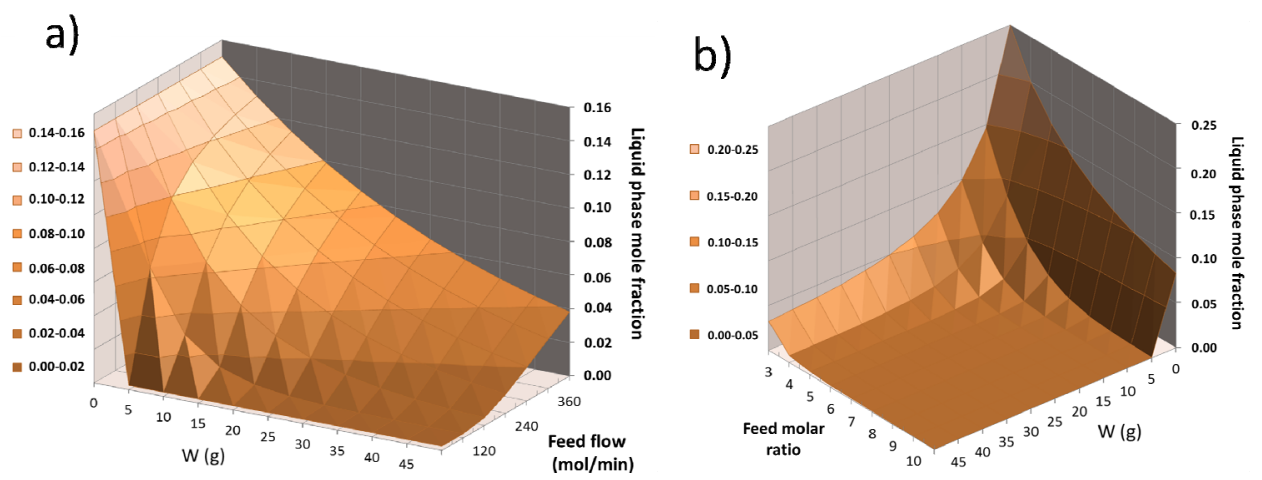

Figure 4 - Surface composition of soybean oil (1) in the liquid phase as a function of feed flow rate by the mass of catalyst (W) (a) and surface composition as a function of feed molar ratio (b).

Hydrolyzate and glycerol generated in the chemical reaction form two phases under mild temperatures. Thus, these products can be separated by decantation or also by centrifugation. 
It can be seen that soybean oil fed to the reactor is almost completely consumed with $50 \mathrm{~g}$ mass catalyst, while excess water in the feed stream leaves the reactor with $40 \%$ molar composition in the output stream. This excess humidity can be removed by flashing in subsequent operations.

From Figure 4 (a), the minimum flow provides the best conversion results. From $100 \mathrm{~mol} /$ min, there is a sharp drop of the soybean oil conversion with increasing feed flow rate. From the feeding molar ratio, Figure 4 (b), the smaller the value of this variable, the lower the processing cost. The stoichiometry of the hydrolysis reaction analyzed between water and soybean oil is $3: 1$. For a value twice of this ratio, the conversion curve has almost stable value. As a way to avoid costly excess water recirculation, it was decided to consider a molar ratio close to $6: 1$, more specifically 5.7.

\subsection{Esterification}

The esterification of soy hydrolyzate (1) with ethanol (2) forming a mixture of esters of Biodiesel (3) and water (4) takes place according to the following stoichiometry:

$$
\text { Hydrolyzate (1) }+\mathrm{C}_{2} \mathrm{H}_{5} \mathrm{OH}(2) \Leftrightarrow \operatorname{Biodiesel}(3)+\mathrm{H}_{2} \mathrm{O}(4)
$$

Here, "biodiesel" refers to the group of esters formed regardless of purity specifications for commercialization. The RDC has 15 stages at ambient pressure. More details of the reactive distillation column and esterification reaction are shown in Table 2.

Table 2 - Specifications for RDC and esterification reaction

\begin{tabular}{|c|c|c|}
\hline Variables & \multicolumn{2}{|c|}{ Specifications } \\
\hline \multirow{2}{*}{ Reflux ratio } & Condenser & 0.001 \\
\cline { 2 - 3 } & Reboiler & 0.14 \\
\hline Reactive sector & & $6^{\circ}-12^{\circ}$ Stages \\
\hline Catalyst & Niobium Oxide $\left(\mathrm{Nb}_{2} \mathrm{O}_{5}\right)$ & $40 \mathrm{~g}$ per stage \\
\hline Feed $(1)$ & $0.366(\mathrm{~mol} / \mathrm{min}), 480.15 \mathrm{~K}$ & Stage 13 \\
\hline Feed $(2)$ & $0.437(\mathrm{~mol} / \mathrm{min}), 351.15 \mathrm{~K}$ & Stage 6 \\
\hline Ahrrenius & Pre-exponential fator & $16.13 / 0.72$ \\
\hline Parameters & Activation energy & $-24,117 \mathrm{~J} / \mathrm{mol}$ \\
\hline
\end{tabular}

Figure 5 shows the liquid phase mole fraction profile to the components of the esterification reaction along the reactive distillation column. From Figure 5, following, it is found that the removal of the desired product, biodiesel, in the bottom is made with considerable purity $(96.54 \%)$. This is due to the use of high heat duty on the reboiler. According to Machado et al. (2013), the reboiler temperature can exceed $260{ }^{\circ} \mathrm{C}$ and could degrade biodiesel formed and removed in the bottom stream. 


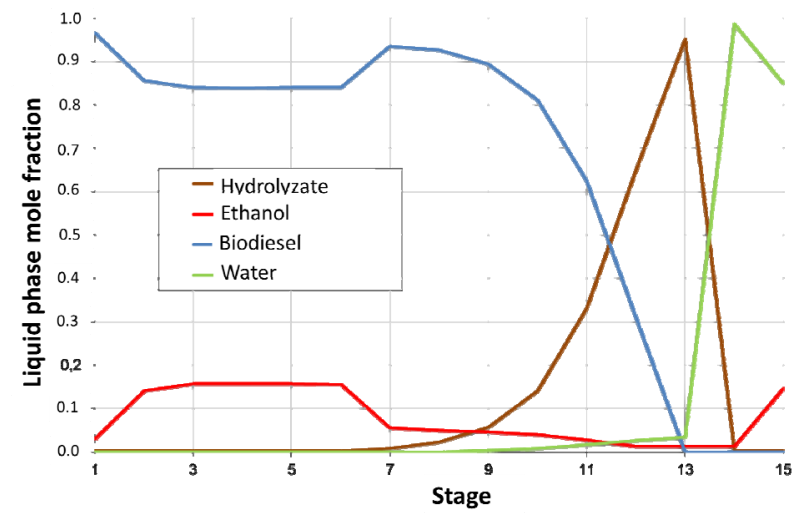

Figure 5 - Liquid phase mole fraction of components to esterification reaction along RDC

In order to obtain the optimum operating parameters of the RDC, the influence of reflux ratio in the condenser and the heat duty on the reboiler were studied. Figure 6 (a) displays a surface with profiles of liquid phase mole fraction against reboiler reflux ratio and Figure 6 (b) shows a surface temperature profile generated in the sensitivity analysis.

a)

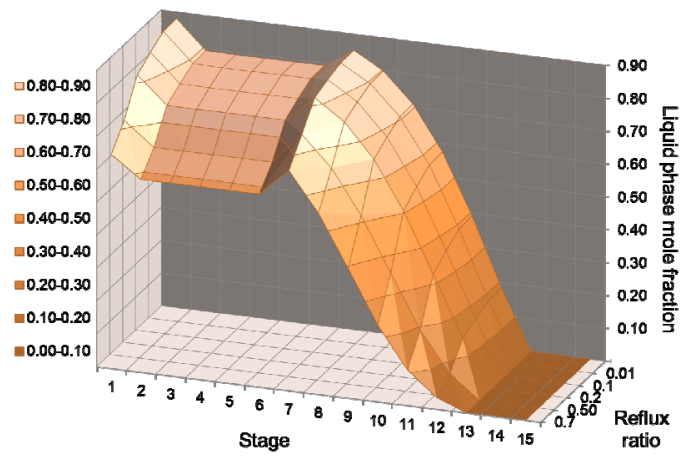

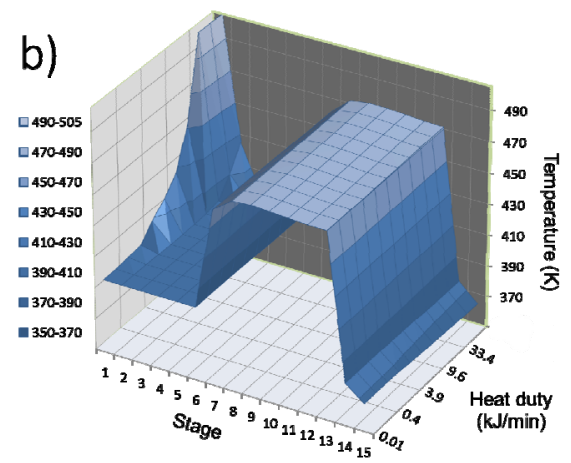

Figure 6 - Liquid phase mole fraction surface of biodiesel (3) along the RDC (a) and surface temperature generated by the variation of the heat duty on the reboiler (b). Sensitivity analysis.

In Figure 6 (a), increasing the value of the reflux ratio at the condenser causes a decrease in biodiesel purity in the bottom of the column and the consequent increase in the water content in the top product. This fact can be explained by higher water retention, which is a product of the chemical reaction inside the column. Thus, a low reflux ratio is suitable.

Figure 6 (b) shows a remarkable change in temperature. At the lower limit, $0.01 \mathrm{~kJ} / \mathrm{min}$ the temperature the bottom product is exposed to is approximately $397 \mathrm{~K}$, while with the upper limit of $57.2 \mathrm{~kJ} / \mathrm{min}$ of thermal load added to the reboiler, the temperature reaches around $599 \mathrm{~K}$. Moreover, the increased heat duty generated in the reboiler increased conversion by only about $2.3 \%$. Therefore, it is not recommend to try to gain efficiency by increasing the heat load. According to Machado et al. (2013), setting the reboiler off and using thermal energy in feed stream can reduce energy consumption and could avoid exposure of bottom product at elevated temperatures. 


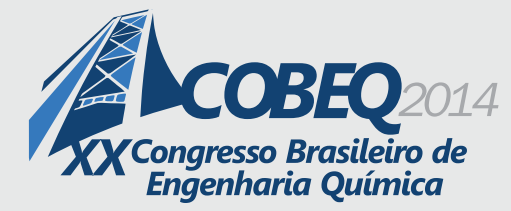

\section{CONCLUSIONS}

In this work, computer simulations are presented for the steps of hydrolysis of fatty matter in a tubular reactor (PBR) and esterification of fatty acids into a reactive distillation column (RDC) for soybean oil biodiesel production. Such steps can be combined in sequence to produce biodiesel by hydro-esterification. The methodology used was consistent and the results of sensitivity analyses showed operating conditions optimized for conversions above $99 \%$, which are higher than the purity of the biodiesel current commercialized according to the applicable regulations in Brazil.

\section{REFERENCES}

ALFRADIQUE, M. F. and CASTIER, M. Automatic generation of procedures for the simulation of reactive distillation using computer algebra. Comp. \& Chem. Eng., v.29, p.1875-1884. 2005.

ARANDA, D. A. G.; GONÇALVES, J. D. A.; PERES, J. S.; RAMOS, A. L. D.; DE MELO, C. A. R.; ANTUNES, O. A. C.; FURTADO, N. C. and TAFT, C. A. The use of acids. niobium oxide. and zeolite catalysts for esterification reactions. J. Phys. Org. Chem. v. 22, p. 709-716, 2009.

CASTIER, M. Automatic implementation of thermodynamic models using computer algebra. Comp. \& Chem. Eng, v.23, p.1229-1245, 1999.

CHEN, F.; HUSS, R.S.; MALONE, M.F.; DOHERTY, M.F. Comp. \& Chem. Eng, v.24, p.24572472, 2000.

DI SERIO, M.; TESSER, R.; PENGMEI, L.; SANTACESARIA, E.; Heterogeneous Catalysts for Biodiesel Production. Energ Fuel. v.22, p. 207-217, 2008.

FOGLER, H. S. Elements of chemical reaction engineering. 3th Edition, Prentice-Hall Book Company, New Jersey, 2002.

GMEHLING, J.; Li, J., Schiller, M. A Modified UNIFAC Model. 2. Present Parameter Matrix and Results for Different Thermodynamic Properties. Ind. Eng. Chem.Res, v.32, p.178-193, 1993.

KISS, A. Novel Process for Biodiesel by Reactive Absorption. Sep. Purif. Technol., v.69, p.280, 2009.

LOTERO, E. et al. Synthesis of biodiesel via acid catalysis. Ind. Eng. Chem. Res. v.44, n. 14, p. 5353-536, 2005.

MA, F.; HANNA, M.A. Biodiesel Production: A Review. Bioresource Technol.. v.70, p. 1-15, 1999.

MACHADO, G. D.; PESSOA, F. L. P.; CASTIER, M.; ARANDA, D. A. G.; CABRAL, V. F; CARDOZO-FILHO, L. Biodiesel Production by Esterification of Hydrolyzed Soybean Oil with Ethanol in Reactive Distillation Columns: Simulation Studies. Ind. Eng. Chem. Res, v. 52, p. 94619469, 2013

ROCHA, L. L. L.; RAMOS, A. L. D.; ANTONIOSI FILHO, N. R.; FURTADO, N. C.; TAFT, C. A.; ARANDA, D. A. G. Production of Biodiesel by a Two-Step Niobium Oxide Catalyzed Hydrolysis and Esterification. Lett. Org. Chem., v. 7, p. 571, 2010. 